Molecules 2000, 5, 1004-1010

\title{
molecules
}

ISSN 1420-3049

(C) 2000 by MDPI

http://www.mdpi.org

\section{Flash Vacuum Pyrolysis of 2,5-Diphenyloxazole}

\author{
Mircea D. Banciu ${ }^{1}$, Daniela Istrati ${ }^{1}$, Dan Mihaiescu $^{1}$ and Constantin Draghici ${ }^{2}$ \\ ${ }^{1}$ Organic Chemistry Laboratory, Polytechnic University Bucharest, Splaiul Independentei 313, 76206 \\ Bucharest, Romania
}

Tel.: (401)-6503289, Fax: (401)-3124573, E-mail: dm_banciu@chim.upb.ro,

URL: http://org1.chim.pub.ro/banciu/

“'C.D. Nenitzescu” - Institute of Organic Chemistry, Romanian Academy, Splaiul Independentei 202B,

71141 Bucharest, Romania

Tel.: (401)-6383665, Fax: (401)-3121601, E-mail: draghici@ ccoux.cco.ro

Received: 28January 2000; revised form 21 July 2000/Accepted: 1 August 2000/Published: 9 August 2000

\begin{abstract}
FVP of the title oxazole (1) at $1000^{\circ} \mathrm{C}$ and $0.5 \mathrm{~mm} \mathrm{Hg}$ afforded a complex reaction mixture containing benzonitrile, phenylacetonitrile, biphenyl, diphenylmethane, fluorene, $o$-benzylbenzonitrile (major product, 22\%), phenanthrene, anthracene, 9,10-anthraquinone, 2-phenylindole and 3-phenylindole. A radical and carbene mechanism was suggested in order to rationalize the formation of the reaction products.
\end{abstract}

Keywords: Flash-vacuum pyrolysis, 2,5-diphenyloxazole, radical reactions, carbenes.

\section{Introduction}

The thermal behaviour of a large variety of heterocyclic compounds has been investigated in connection with mechanistic and/or synthetic studies [1-3]. Though flash-vacuum pyrolyses (FVP) of a few substituted and annulated isoxazoles [4-6] as well as of different isoxazolones [7-9] were investigated (revealing the preferential fission of the $\mathrm{N}-\mathrm{O}$ bond, and the extrusion of $\mathrm{CO}_{2}$, respectively) reports on the gas-phase chemistry of oxazoles are very scarce. Thus, it has been proved that unsubstituted oxazole radical cation dissociates by elimination of a hydrogen atom [10] whereas 2-phenyl-1,3-oxazol5(4H)-one thermally eliminates $\mathrm{CO}_{2}$ [11]. In order to provide supplementary data concerning FVP of oxazoles and in continuation of our previous investigations of FVP of hydrocarbons [12] and heterocycles [13], we intend to study the thermal behaviour of a series of substituted oxazoles. In the present paper we describe the results of FVP of 2,5-diphenyloxazole (1). 


\section{Results and Discussion}

The pyrolyses of diphenyloxazole 1 were performed in a flow-system under argon atmosphere at 0.5 $\mathrm{mm} \mathrm{Hg}$, the calculated contact times being $\leq 0.2 \mathrm{~s}$. Under these conditions the oxazole 1 showed a high thermal stability. Whereas at $800^{\circ} \mathrm{C}$ a conversion of only $9 \%$ was achieved, the increase of temperature at $1000^{\circ} \mathrm{C}$ brought the conversion to $91 \%$. The reaction products were examined by GC/MS analysis and by ${ }^{1} \mathrm{H}$ - and ${ }^{13} \mathrm{C}$-NMR spectroscopy. The product distribution was a very complex one. The pyrolysis products are shown in Scheme 1 in the order of their elution from the GC column.
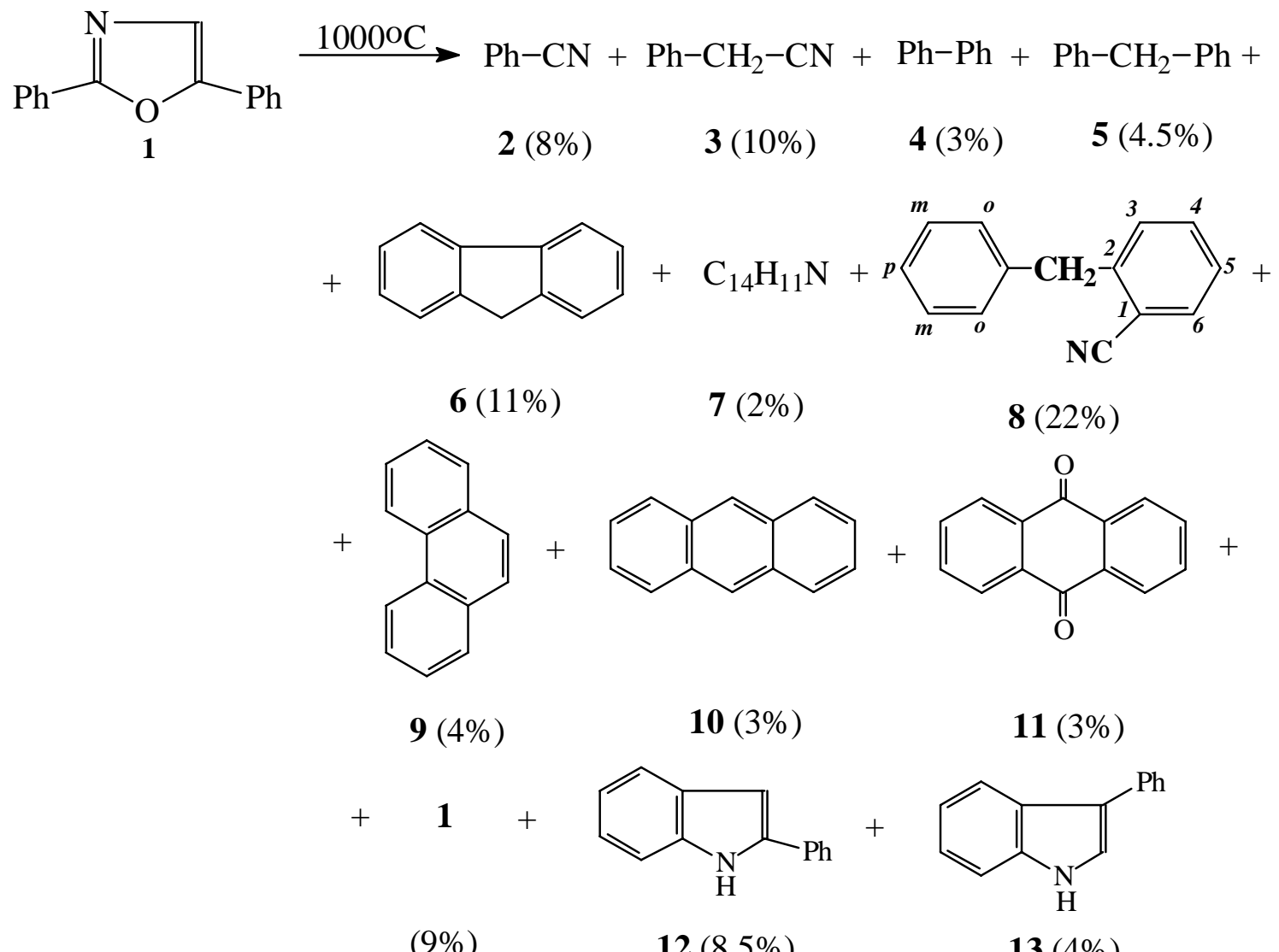

\section{Scheme 1.}

From the reaction products compounds 2-6 and 9-13 were identified by their characteristic mass spectra which were favourably compared with the mass spectra of authentic specimens. For compounds 2, 3, 4, 6, 9, 10 and 11 mixed GC analysis of mixtures of the pyrolysis product with authentic samples also confirmed the proposed structures. Compound $\mathbf{8}$, the main pyrolysis product, was separated by column chromatography on silica and identified through its spectral data (see also Experimental) as follows: the infrared spectrum indicated the characteristic absorption of a CN group $\left(2231 \mathrm{~cm}^{-1}\right)$ along with those of $\mathrm{CH}_{2}$ groups and aromatic moieties. In the ${ }^{1} \mathrm{H}-\mathrm{NMR}$ spectrum a singlet at $\delta=4.21 \mathrm{ppm}$ can be attributed to the $\mathrm{CH}_{2}$ protons (the deshielding of $0.25 \mathrm{ppm}$ as compared to diphenylmethane being due to the ortho- $\mathrm{CN}$ group). Doping the sample of $\mathbf{8}$ with $\mathrm{Eu}(\mathrm{fod})_{3}$ shift reagent led to a larger molar induced shift (1.9) for $\mathrm{H}^{6}$ than for $\mathrm{H}^{3}-\mathrm{H}^{5}$. A molar induced shift of 1.4 was observed for $\mathrm{CH}_{2}$ protons situated in the vicinity of the $\mathrm{CN}$ complexing group. The ${ }^{13} \mathrm{C}-\mathrm{NMR}$ spectrum of $\mathbf{8}$ indicated the signal of $\mathrm{CH}_{2}$ at $\delta=40.21 \mathrm{ppm}$ and that of $\mathrm{CN}$ at $\delta=118.11 \mathrm{ppm}$. The ${ }^{13} \mathrm{C}$ chemical shifts of all carbon 
atoms calculated using known increments agree well with the experimental values. Compound 7, occuring in a small amount (2\%), seems to be a steric isomer of $\mathbf{8}$, giving $\mathrm{M}=193$ and a molecular formula of $\mathrm{C}_{14} \mathrm{H}_{11} \mathrm{~N}$ (probably possessing the $-\mathrm{CN}$ group in the para position). The increased thermal stability of diphenyloxazole 1 is due to the lack of easily eliminable moieties (like e.g. $\mathrm{N}_{2}$ or $\mathrm{CO}_{2}$ in other heterocycles) as well as in the absence of bonds particularly prone to cleavage (like the $\mathrm{N}-\mathrm{O}$ bond in isoxazoles). The two phenyl substituents conjugated with the oxazole ring also contribute to the stability of $\mathbf{1}$.

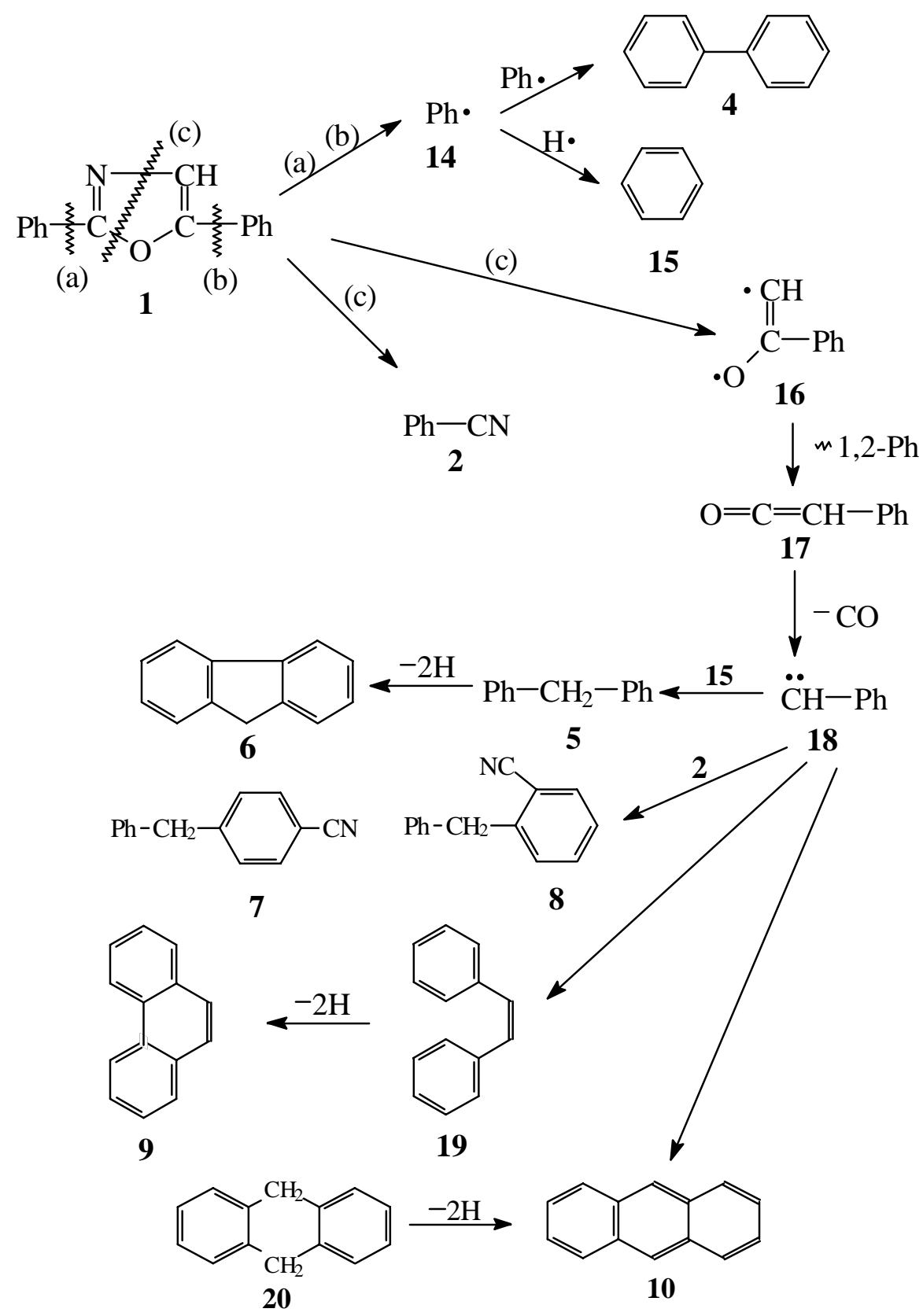

Scheme 2.

In order to rationalize the formation of the main pyrolysis products a reaction scheme including more competing pathways can be proposed (Scheme 2). Compounds 2, 4-10 can be generated from 1 by bond cleavage routes denoted (a), (b), (c) in Scheme 2. Generation of free radicals seems to be favoured by the reaction conditions $\left(1000^{\circ} \mathrm{C}\right.$; quartz apparatus). Phenyl radicals can generate biphenyl (4) and 
benzene (identified in traces), whereas fission (c) affords benzonitrile (2). On the other hand, in the diradical 16 an usual 1,2-phenyl migration could lead to the intermediate occurrence of phenylketene 17. Thermal decarbonylations of ketenes to carbenes are well-known processes [14]. The phenylcarbene 18, generated from $\mathbf{1 7}$ can be the precursor of 5 and $\mathbf{6}$ (by insertion and hydrogen elimination), of $\mathbf{7}$ and $\mathbf{8}$ (by insertion) and of $\mathbf{9}$ and $\mathbf{1 0}$ (by dimerisation respectively double insertion followed by dehydrogenation). Previous work by Hedaya [15] has shown that the reaction products of phenylcarbene - generated from phenyldiazomethane - are strongly determined by the reaction conditions employed, especially by the temperature (the increase of anthracene at $900^{\circ} \mathrm{C}$ being underlined).

\section{Conclusions}

The high thermal stability and the narrow temperature interval of pyrolysis of 2,5-diphenyloxazole were demonstrated. Among the twelve identified pyrolysis products, the most abundant $(22 \%)$ is $o$ benzylbenzonitrile. The suggested reaction mechanism will be further tested and/or detailed by investigation of other substituted oxazoles.

\section{Experimental}

\section{General}

Melting points are uncorrected. The NMR spectra were registered on a Varian Gemini 300 apparatus at $300 \mathrm{MHz}$ for ${ }^{1} \mathrm{H}$ and at $75 \mathrm{MHz}$ for ${ }^{13} \mathrm{C}$, using TMS as internal standard. The GC/MS analyses were performed on a Varian 3400 gas chromatograph with split/splitless injector coupled with a Varian Saturn II mass spectrometer provided with ion trap. A capillary DB-5 column (30m length, $0.25 \mathrm{~mm}$ internal diameter) was used. The analysis conditions were: injector temperature $250^{\circ} \mathrm{C}$, split rate $1: 50$, temperature program $50-250^{\circ} \mathrm{C}$ at $7^{\circ} / \mathrm{min}$, then $20 \mathrm{~min}$. at $250^{\circ} \mathrm{C}$, carrier gas helium with flow-rate 1 $\mathrm{mL} / \mathrm{min}$., temperature of transfer line $200^{\circ} \mathrm{C}$, trap temperature $170^{\circ} \mathrm{C}$, electron ionization $70 \mathrm{eV}$.

\section{2,5-Diphenyloxazole (1)}

M.p. $71-72^{\circ} \mathrm{C}$, was a commercially available product (Aldrich).

\section{FVP of 2,5-Diphenyloxazole}

All FVP were performed in a flow system using a previously described apparatus [16]. The pyrolysis quartz tube (60 cm length, $10 \mathrm{~mm}$ diameter) was filled with quartz chips on $30 \mathrm{~cm}$ length; this zone was heated with a cylindrical electric oven. The temperature was continously measured by means of a thermocouple and the pressure $(0.5 \mathrm{~mm} \mathrm{Hg})$ with a McLeod manometer. The oxazole sample (usually 30 $\mathrm{mg}$ ) was sublimed under argon flow (4 $\mathrm{mL} / \mathrm{min}$.) in the pyrolysis zone. The reaction products accumulated at the cooled end of the quartz tube were dissolved in chloroform, the solvent was evaporated in vacuo and the residue (about $85 \%$ yield) was subjected to GC/MS analysis. Pyrolysis of $\mathbf{1}$ at $800^{\circ} \mathrm{C}$ conducted to only $9 \%$ conversion. Working at $1000^{\circ} \mathrm{C}$ a conversion of $91 \%$ was achieved. The reaction products in this case were, in order of their elution from GC column: benzene (15) (only traces due to its high volatility); benzonitrile (2) - 8\%; phenylacetonitrile (3) - 10\%; biphenyl (4) - 3\%; diphenyl- 
methane (5) - 4.5\%; fluorene (6) - 11\%; unknown component with $\mathrm{M=193} \mathrm{(7)} \mathrm{-} \mathrm{2 \%} \mathrm{(probably} \mathrm{the} \mathrm{para}$ isomer of 8); $o$-benzylbenzonitrile (8) - 22\%; phenanthrene (9) - 4\%; anthracene (10) - 3\%, 9,10anthraquinone (11) - 3\%; unreacted oxazole 1 - 9\%; 2-phenylindole (12) - 8.5\% and 3-phenyl-indole (13) $-4 \%$. Along with these products, representing $92 \%$ from the reaction mixture, only minor components $(<2 \%)$ were observed in the gas-chromatogram. These minor components were not further investigated. From the above reaction products the compounds 2-6 and 9-13 were identified by their characteristic mass spectra which were favourably compared with the mass spectra of authentic specimens registered in the GC/MS library. For some reaction products $(\mathbf{2}, \mathbf{3}, \mathbf{4}, \mathbf{6 ,}, \mathbf{9}, 10$ and 11) mixed GC samples of pyrolysis product with authentic specimens confirmed the proposed structures. The mass spectra of components $\mathbf{5 , 7 , 8 , 1 2}$ and $\mathbf{1 3}$ are given below:

\section{Diphenylmethane (5)}

Mass spectrum (m/z; relative abundance \%): 27 (3); 38 (3); 39 (15); 50 (6); 51 (9); 62 (2); 63 (8); 65 (11); 76 (2); 77 (3); 83 (2); 89 (9); 90 (3); 91 (40); 92 (3); 102 (2); 113 (2); 115 (10); 126 (2); 128 (4); 139 (5); 141 (3); 151 (2); 152 (25); 153 (30); 154 (4); 163 (3); 164 (4); 165 (37); 166 (11); 167 (100; P.I.; M); 168 (87; M+1); 169 (10; M+2).

\section{Benzylbenzonitrile (7)}

Mass spectrum (m/z; relative abundance \%): 26 (6); 27 (9); 28 (59); 38 (8); 39 (21); 50 (26); 51 (43); 52 (7); 62 (10); 63 (21); 74 (9); 75 (8); 76 (16); 77 (19); 87 (5); 88 (7); 89 (32); 90 (9); 102 (6); 115 (12); 116 (14); 139 (6); 151 (6); 152 (12); 163 (5); 164 (6); 165 (90); 166 (35); 167 (7); 176 (6); 177 (6); 178 (37); 179 (50); 180 (43); 181 (7); 190 (6); 191 (6); 192 (24); 193 (100; P.I.; M); 194 (21; $\mathrm{M}+1) ; 195(0.5 ; \mathrm{M}+2)$.

\section{o-Benzylbenzonitrile (8)}

Mass spectrum (m/z; relative abundance \%): 27 (3); 37 (2); 38 (3); 39 (11); 50 (6); 51 (8); 52 (2); 62 (3); 63 (8); 64 (2); 65 (7); 74 (2); 75 (3); 76 (3); 77 (3); 87 (2); 88 (2); 89 (9); 90 (4); 91 (7); 113 (2); 115 (3); 116 (4); 118 (2); 139 (3); 140 (3); 145 (3); 151 (2); 152 (4); 163 (5); 164 (5); 165 (43); 166 (8); 177 (3); 178 (4); 179 (4); 180 (6); 190 (8); 191 (5); 192 (27); 193 (100; P.I.; M); 194 (21; M+1); $195(2 ; \mathrm{M}+2)$.

\section{2-Phenylindole (12)}

Mass spectrum (m/z; relative abundance \%):. 27 (2); 38 (2); 39 (5); 50 (3); 51 (3); 62 (2); 63 (3); 74 (2); 82 (2); 83 (2); 87 (2); 89 (3); 90 (2);115 (2); 139 (3); 163 (5); 164 (6); 165 (27); 166 (5); 167 (2); 190 (2); 191 (4); 192 (15); 193 (100; P.I.; M); 194 (16; M+1); 195 (1; M+2).

\section{3-Phenylindole (13)}

Mass spectrum (m/z; relative abundance \%):. 39 (4); 50 (2); 51 (2); 63 (3); 89 (7); 90 (3); 139 (2); 163 (2); 164 (2); 165 (17); 166 (3); 167 (2); 190 (2); 191 (4); 192 (14); 193 (100; P.I.; M); 194 (16; 
$\mathrm{M}+1) ; 195(1 ; \mathrm{M}+2)$.

For preparative purposes the products of four identical pyrolyses at $1000^{\circ} \mathrm{C}$ were combined and subjected to liquid chromatography on a silica column (Merck 60; 35-70 mesh) using petroleum ether: diethylether (95:5) as eluent. The separated $o$-benzylbenzonitrile (thick oil; lit. m.p. [17] $=19^{\circ} \mathrm{C}$ ) gave the following spectral data:

IR Spectrum $\left(\mathrm{CCl}_{4} ; \mathrm{cm}^{-1}\right): 1458\left(\delta_{\mathrm{CH}_{2}}\right) ; 2231\left(\mathrm{v}_{\mathrm{CN}}\right) ; 2853\left(\delta_{\mathrm{CH}_{2}}{ }^{\mathrm{sim}}\right) ; 2961\left(\delta_{\mathrm{CH}_{2}}{ }^{\text {asim }}\right) ; 3025$ and 3061 $\left(\delta_{\mathrm{CH}}\right)$.

${ }^{l} H$-NMR Spectrum $\left(\mathrm{CDCl}_{3}, \delta\right.$ ppm, J Hz;): $4.21\left(\mathrm{~s} ; 2 \mathrm{H} ; \mathrm{CH}_{2}\right) ; 7.20-7.35\left(\mathrm{~m} ; 7 \mathrm{H} ; \mathrm{C}_{6} \mathrm{H}_{5} ; \mathrm{H}^{5} ; \mathrm{H}^{3}\right) ; 7.49$ $\left(\mathrm{td} ; 1 \mathrm{H} ; 7.7 ; 1.5 ; \mathrm{H}^{4}\right) ; 7.63\left(\mathrm{dd} ; 1 \mathrm{H} ; 1.4 ; \mathrm{H}^{6}\right)$.

${ }^{13} C$-NMR Spectrum $\left(\mathrm{CDCl}_{3}, \delta \mathrm{ppm},\right)$ : $40.21\left(\mathrm{CH}_{2}\right) ; 112.67\left(\mathrm{C}^{1}\right) ; 118.11(\mathrm{CN}) ; 126.71\left(\mathrm{CH}^{\mathrm{para}}\right) ; 126.77$ $\left(\mathrm{C}^{5}\right) ; 128.72\left(2 \mathrm{CH}^{\text {meta }}\right) ; 128.98\left(2 \mathrm{CH}^{\text {ortho }}\right) ; 130.05\left(\mathrm{C}^{3}\right) ; 132.83\left(\mathrm{C}^{6}\right) ; 132.90\left(\mathrm{C}^{4}\right) ; 138.79\left(\mathrm{C}_{\text {quart }}\right) ; 144.98$ $\left(\mathrm{C}^{2}\right)$.

Acknowledgements: The authors express their thanks to Professor Iosif Schiketanz for a sample of 2,5diphenyloxazole and to Professor Alexandru T.Balaban for helpful discussions.

\section{References and Notes}

1. Brown, R.F.C. Pyrolytic Methods in Organic Chemistry; Academic Press: New York, 1980; 247281, pp 328-335.

2. Braslavsky, S.; Heicklen, J. The Gas-Phase Thermal and Photochemical Decomposition of Heterocyclic Compounds Containing Nitrogen, Oxygen or Sulfur. Chem. Rev. 1977, 77, 473-511.

3. McNab, H. Synthetic Applications of Flash Vacuum Pyrolysis. Contemp. Org. Synth. 1996, 3, 373396.

4. Aldous, G.L.; Bowie, J.H.; Thompson, M.J. Thermal Rearrangements of 3,5-Diphenylisoxazole. J. Chem. Soc. Perkin Trans. I, 1976, 16-19.

5. Flammang, R.; Laurent, S.; Flammang-Barbieux, M.; Wentrup, C. Formation and Identification of Ionized and Neutral Cumulenes, RN:C:C:C:NH, by Tandem Mass Spectrometry. Org. Mass Spectrom. 1993, 28, 1161-1166.

6. Kappe, C.O.; Flamming, R.; Wentrup, C. Synthesis and Flash Vacuum Pyrolysis of Isoxazolo[4,5d] pyrimidines. Heterocycles 1994, 37, 1615-1622.

7. Khalafy, J.; Prager, R.H. Flash Vacuum Pyrolysis of some N-Benzylbenzotriazoles and N-Benzylbenzisoxazolones. Aust. J. Chem. 1998, 51, 925-929.

8. Prager, R.H.; Singh, Y. The Chemistry of 5-Oxodihydroisoxazoles. VII. Conversion of Heterocyclyloxazol-5(4H)-ones to Imidazoles by Flash Vacuum Pyrolysis. Tetrahedron 1993, 49, 81478158.

9. Clark, A.D.; Janowski, W.K.; Prager, R.H. Unusual Rearrangements of 2-aroylimidoyl-2-phenylethylidene to 2,5-disubstituted Oxazoles. Tetrahedron 1999, 55, 3637-3648.

10. Flammang, R.; Plisnier, M.; Bouchoux, G.; Happilliard, Y.; Humbert, S.; Wentrup, C. Unimolecular Chemistry of Oxazole and Isoxazole Radical Cations in the Gas Phase. Org. Mass Spectrom. 1992, 27, 317-325.

11. Lesniak, S.; Mloston, G.; Heimgartner, H. Flash Vacuum Pyrolysis of 1,3-Thiazole-5(4H)-thiones. 
Pol. J. Chem. 1998, 72, 1915-1920.

12. Balaban, A.T.; Banciu, D.M.; Ciorba, V. Annulenes-, Benzo-, Hetero-, Homo-Derivatives and their Valence Isomers; CRC Press: Boca Raton, Fla. 1987; Vol. II, pp 196-203.

13. Banciu, D.M.; Popescu, A.; Simion, A.; Draghici, C.; Mangra, C.; Mihaiescu, D.; Pocol, M. FlowVacuum Pyrolysis of Tetrazoles with Annelated Dibenzocycloalkane Skeletons. J. Anal. Appl. Pyrolysis 1999, 48, 129-146.

14. Brown, R.F.C. Pyrolytic Methods in Organic Chemistry; Academic Press: New York, 1980; pp 110, 119, 120-121.

15. Schissel, P.; Kent, M.E.; McAdoo, D.J.; Hedaya, E. Flash-Vacuum Pyrolysis. VII. Fulvenallene. The Ring Contraction and Expansion of Phenylcarbene. J. Amer. Chem. Soc. 1970, 92, 2147-2149.

16. Banciu, D.M.; Stanescu, M.D.; Florea, C.; Petride, A.; Draghici, C., Cioranescu, E. Benzoannelated Valence Isomers of Homoannulenes. I. Thermal Behaviour of some Dibenzo $\left(\mathrm{C}_{10} \mathrm{H}_{9}\right)$ hydrocarbons. Bull. Soc. Chim. Fr. 1991, 128, 919-925.

17. Cassirer, H. Zur Kenntniss der o-Cyano- und o-Nitrobenzylchloride. Chem. Ber. 1892, 25, 30813030 .

Sample Availability: Available from the authors.

(C) 2000 by MDPI (http://www.mdpi.org). 